\title{
QUALIDADE DE SEMENTES DE JILÓ (SOLANUM GILO RADDI - SOLANACEAE) ARMAZENADAS EM AMBIENTE NÃO CONTROLADO ${ }^{1}$
}

\author{
Carlos Manoel de Oliveira
}

\begin{abstract}
RESUMO
Os setores de produção e de conservação de sementes dependem diretamente de trabalhos que determinem as melhores condições de armazenamento e que, consequentemente, garantam o maior período possível de manutenção da qualidade fisiológica da semente. Em regiões tropicais, há uma maior limitação no que tange à manutenção da qualidade fisiológica durante o período de armazenamento, principalmente em ambiente não controlado, cuja variação das condições ambientais pode influenciar sobremaneira a qualidade final de um lote de sementes. Objetivou-se, com o presente trabalho, avaliar a qualidade de sementes de duas cultivares de jiló (Solanum gilo Raddi), armazenadas em condições ambientais não controladas. O delineamento experimental utilizado foi o de blocos casualizados com 5 repetições, em esquema fatorial 2x5, sendo duas cultivares de jiló (Morro Grande e Português) e 5 períodos de armazenamento $(0,30,60,90$ e 120 dias de armazenamento). Avaliou-se a porcentagem de germinação, a porcentagem de emergência, o Índice de Velocidade de Emergência, o Coeficiente de Variação no Tempo, o Tempo Médio da Emergência, os Índices de Incerteza e de Sincronia da Emergência e a Frequência Relativa da Emergência de plântulas. A cultivar Português se apresentou com os melhores índices de porcentagem de germinação, porcentagem de emergência, índice de velocidade de emergência, tempo médio da emergência e coeficiente de variação do tempo da emergência, quando as sementes foram armazenadas por até dias em ambiente não controlado. A cultivar Português é indicada aos produtores de jiló visando produção de mudas, pois se mostrou superior a cultivar Morro Grande quando armazenadas por até 30 dias em ambiente não controlado. Após 30 dias de armazenamento, a utilização de sementes das duas cultivares não é indicado, pois a porcentagem de germinação cai consideravelmente.
\end{abstract}

Palavras-Chave: Fitotecnia. Produção de sementes. Armazenamento.Viabilidade.

\section{SEED QUALITY OF SCARLET EGGPLANT STORED IN ENVIRONMENTAL CONDITIONS NOT CONTROLLED.}

\begin{abstract}
${ }^{1}$ Como citar este artigo: OLIVEIRA, C. M. Qualidade de sementes de jiló (Solanum gilo Raddi - Solanaceae) armazenadas em ambiente não controlado. ForScience, Formiga, v. 8, n. 1, e00663, jan./jun.2020. DOI: 10.29069/forscience.2020v8n1.e663.
\end{abstract}

${ }^{2}$ Autor para correspondência: Carlos Manoel Oliveira, e-mail: carlos.manoel@ifmg.edu.br 
The sectors of production and conservation of seeds depend directly from studies that determine the best storage conditions and that consequently guarantee the longest possible period of maintenance of physiological quality of seed. In tropical regions, there is a major limitation regarding the maintenance of physiological quality during storage period mainly in uncontrolled environment, whose variation of environmental conditions can greatly influence the final quality of a seed lot. The objective of this final paper was to evaluate the quality of seeds of two cultivars of scarlet eggplant (Solanun gilo Raddi), stored in environmental conditions not controlled. The experimental design used was randomized blocks with 05 replications in a factorial $2 \times 5$, being two cultivars of scarlet eggplant (Morro Grande and Portuguese) and 05 storage periods (0,30, 60, 90 and 120 days of storage). Was evaluated the Percentage of Germination, Percentage of Emergence, Emergence Speed Index, Coefficient of Variation of the Time, Average Time of Emergency, Indexes of Uncertainty and Sync the Emergence and Relative Frequency of Seedling Emergence in the time. The Portuguese cultivar presented the best rates of Germination Percentage, Emergency Percentage, Emergency Speed Index, Average Emergence Time and Emergence Time Variation Coefficient, when seeds were stored for up to 30 days in an uncontrolled environment. The Portugues cultivar is indicated to jiló producers aiming seedling production because it was superior to Morro Grande cultivar when stored for up to 30 days in an uncontrolled environment. After 30 days of storage, the use of seeds from both cultivars is not indicated because the germination percentage drops considerably.

Keywords: Phytotechny. Seed production. Storage. Viability.

\section{INTRODUÇÃO}

A família Solanaceae compõe um dos maiores grupos dentre as plantas vasculares, contando com 98 gêneros e um número aproximado de 2400 espécies (D’ARCY, 1991; HUNZIKER, 2001). Introduzido no Brasil pelos escravos, o jiloeiro (Solanun gilo Raddi) é uma hortaliça tipicamente tropical, muito exigente em calor, bastante apreciada e altamente consumida em algumas regiões do país (FILGUEIRA, 1987). É cultivado, principalmente, nos estados do Rio de Janeiro, Minas Gerais, Espírito Santo e São Paulo (PESAGRO-RIO; EMATER-RIO, 1989).

O fruto do jiló é colhido para consumo ainda imaturo, possuindo intenso sabor amargo e coloração verde (CAMARGO, 1992). Comparado a outras hortaliças, como o tomate e o pimentão, da própria família Solanaceae, existem poucas empresas que se dedicam à produção de sementes de jiló. Devido à falta de tecnologia, os produtores de jiló ficam dependentes de poucas cultivares disponíveis no mercado. Diante disso, é mais comum um produtor de jiló salvar as suas sementes do que um produtor de tomate. Em hortaliças de frutos carnosos, como jiló, berinjela e tomate, a maturidade das sementes geralmente coincide com o início da mudança de 23 colorações dos frutos. Vale salientar ainda que as sementes podem atingir a maturidade após a colheita dos frutos, quando estes passam por um período 
de descanso ou repouso, que varia de 7 a 10 dias, em local fresco e ventilado, antes da extração das sementes. Neste caso, sementes imaturas ainda presentes no fruto completam o seu desenvolvimento, resultando em melhor qualidade fisiológica e maior rendimento (DIAS, 2001).

Quando o produtor opta por salvar suas sementes para utilizar no próximo plantio, os frutos são colhidos maduros, com coloração avermelhada e em ponto de maturação de fisiológica.

Como o jiló é uma hortaliça de grande interesse econômico e comercial, é fundamental a atenção na produção de suas sementes, sendo preciso conhecer os cuidados necessários após a colheita, como a secagem ideal e o armazenamento adequado.

$\mathrm{O}$ armazenamento de sementes nas regiões tropicais é uma das maiores limitações à manutenção da sua qualidade fisiológica. A capacidade de armazenamento pode variar entre espécies, bem como entre e dentro dos lotes de sementes (GROOT et al., 2003). Vários são os fatores que influenciam a conservação da viabilidade e do vigor das sementes durante o armazenamento. Dentre eles, têm-se a qualidade fisiológica inicial das sementes, o vigor da planta-mãe, as condições climáticas durante a maturação, os danos mecânicos, as condições de secagem, a umidade relativa (UR) do ar, a temperatura de armazenamento, a ação de fungos e insetos, os tipos de embalagem e o tempo de armazenamento (CARVALHO; NAKAGAWA, 2000).

A deterioração de sementes durante o armazenamento ocorre em consequência de uma combinação de três fatores principais: período de armazenamento, temperatura do ambiente e grau de umidade das sementes (ROBERTS, 1973; ELLIS, 1980). Estas variações ambientais, às quais as sementes estão sujeitas durante o armazenamento, podem interferir diretamente na qualidade fisiológica, causando deterioração e acarretando problemas na produção futura (SILVA et al., 2011). A temperatura de armazenamento é um dos fatores que afetam diretamente a velocidade das reações químicas nas sementes, acelerando a respiração e o desenvolvimento de microorganismos e a redução da temperatura beneficia a conservação das sementes ortodoxas (MARCOS FILHO, 2015).

Segundo Delouche et al (1973), as condições de armazenamento em um período de oito a dez meses devem ser seguras visando garantir a manutenção do potencial fisiológico das sementes, sem perda de vigor, mediante uma combinação da soma da umidade relativa do ar e temperatura, cujo resultado deve ser inferior a 80. A redução da capacidade de germinação de sementes após determinado período de armazenamento é observada por 
diversos trabalhos com diferentes espécies, sendo a redução da qualidade fisiológica o fator principal das transformações características da deterioração (POPINIGIS, 1985).

Nakada et al. (2010), avaliando o desempenho de sementes de pepino durante o armazenamento, constataram que ocorre redução da qualidade fisiológica após seis meses de armazenamento. A redução da qualidade durante o armazenamento pode ocorrer em várias espécies. Especificamente para o jiloeiro, a aquisição das sementes junto ao produtor rural para produção de mudas e, posteriormente, para produção de frutos é feita, de maneira geral, por meio de cooperativas, companhias particulares ou coletadas pelos próprios produtores, que se utilizavam de sementes provenientes das sobras de frutos colhidos do ano anterior, valendo-se de processos empíricos, que são passados de geração para geração. Essas sementes são denominadas de salvas ou próprias, e sua manutenção, de forma viável, está diretamente relacionada à maneira como esses agricultores as armazenam entre as safras. A sua qualidade sofre grande influência do período e das condições nas quais permanecem acondicionadas entre a colheita e a semeadura. Porém, para estes agricultores produzirem sementes para uso próprio, com qualidade superior, é difícil, pois não dispõem de mão de obra, tecnologia e área reservada (CARRARO, 2004).

Sendo assim, objetivou-se com o presente trabalho avaliar a qualidade de sementes de duas cultivares de jiló (Solanun gilo Raddi), armazenadas em condições ambientais não controladas.

\section{MATERIAL E MÉTODOS}

A coleta das sementes foi feita no Setor de Produção de Olericultura do Instituto Federal de Educação, Ciência e Tecnologia de Minas Gerais (IFMG) - Campus Bambuí em plantas adultas de jiloeiro em fase de dispersão e com frutos apresentando-se maduros e sementes em ponto de maturidade fisiológica (PIÑA-RODRIGUES; FIGLIOLIA, 1993) e o experimento conduzido no Laboratório de Tecnologia de Sementes (LABTS) do IFMG Campus Bambuí entre os meses de outubro de 2015 a fevereiro de 2016.

As sementes foram lavadas e secas a temperatura ambiente, acondicionadas em papel Kraft e armazenadas em condições ambientais não controladas conforme Figura 1. O delineamento experimental utilizado foi o de blocos casualisados, com cinco repetições, em esquema fatorial 2 x 5, sendo 2 cultivares de jiló: Português e Morro Grande e, 5 períodos de armazenamento das sementes (sementes não armazenadas e sementes armazenadas por 30, 60, 90 e 120 dias após a colheita). 


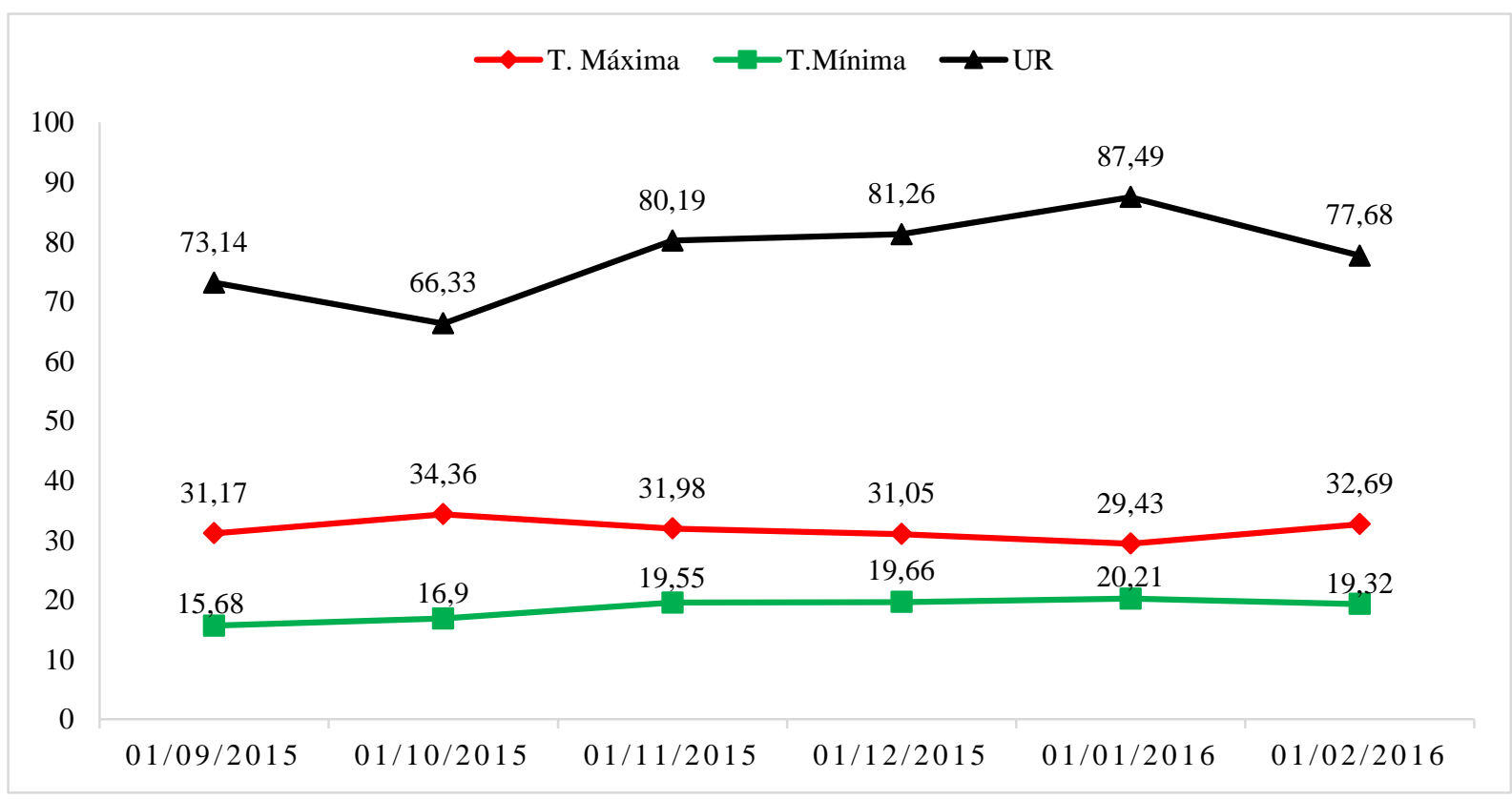

Figura 1- Dados de temperatura máxima e mínima $\left({ }^{\circ} \mathrm{C}\right)$ e de umidade relativa do ar $(\%)$ durante o período de armazenamento de sementes de jiló em condições ambientais não controladas, Bambuí/MG, 2016

Fonte: Inmet (2016).

Para as avaliações do experimento, foi utilizado o teste de germinação, com 04 subamostras de 50 sementes por tratamento, acondicionadas em caixas gerbox sobre substrato de papel tipo "Germitest", à temperatura de $25^{\circ} \mathrm{C}$. A quantidade de água adicionada às caixas foi de 2,5 vezes a massa do papel seco, visando umedecimento adequado e uniformização do teste.

A porcentagem de germinação foi determinada por meio da contagem do número de plântulas normais ao sexto e ao décimo quarto dia conforme prescrição das Regras para Análise de Sementes (BRASIL, 2009). Para avaliar as medidas de emergência, foi realizada a semeadura em canteiros com areia de textura média, lavada e solarizada do setor de produção de mudas do IFMG - Campus Bambuí. Na avaliação, consideraram-se 200 sementes por parcela divididas em quatro linhas de um metro de comprimento com subparcelas de 50 sementes por linha, marcadas sobre o leito de areia nivelada. Uma vez semeadas, o material foi coberto com uma camada de areia de um centímetro. Foram realizados os cálculos de vazão de água do sistema de irrigação e da capacidade de retenção de água da areia dos canteiros. Com base nesses resultados, a irrigação foi feita de forma a manter a umidade em $60 \%$ da capacidade de retenção de água da areia. Entre o início da emergência das primeiras plântulas até a estabilização do estande, a leitura foi realizada a cada 12 horas, em que se 
contou o número de plântulas emersas. Como emersas, foram consideradas plântulas cujos cotilédones que não mais se tocavam o leito da areia.

A coleta das medidas e as expressões empregadas na análise da emergência foram realizadas segundo Santana e Ranal (2004). A porcentagem de Emergência (E) é o percentual entre o número de plantas emergidas e o número total de sementes conforme descrito na Equação (1).

$$
E(\%)=\frac{E}{N} 100
$$

Onde Eé o número de plântulas emergidas e $N$ é o número total de sementes utilizadas na semeadura. A Equação (2) expressa o Índice de Velocidade de Emergência (IVE), cujo resultado é o somatório do número de plântulas emergidas por cada dia, prevendo-se o vigor relativo de uma amostra de sementes segundo a expressão proposta por Maguire (1962).

$$
\mathrm{IVE}=\frac{\mathrm{E} 1}{\mathrm{~N} 1}+\frac{\mathrm{E} 2}{\mathrm{~N} 2}+\frac{\mathrm{E} 3}{\mathrm{~N} 3}+\frac{\mathrm{E} 4}{\mathrm{~N} 4}+\ldots+\frac{\mathrm{En}}{\mathrm{Nn}}
$$

Onde E1, E2,...En é o número de plântulas emergidas no dia $\mathrm{N} 1, \mathrm{~N} 2, \ldots \mathrm{Nn}$ da leitura da emergência. O Tempo Médio da Emergência (Tm) conforme descrito na Equação (3) é calculado como média ponderada dos tempos de emergência, utilizando como peso de ponderação o número e plântulas emersas nos intervalos de tempo que foram estabelecidos na coleta de dados segundo a expressão proposta por Labouriau (1983).

$$
\mathrm{Tm}=\frac{\sum_{\mathrm{i}=1}^{\mathrm{k}} \text { ni.ti }}{\sum_{\mathrm{i}=1}^{\mathrm{k}} \mathrm{ni}}
$$

O Coeficiente de Variação do Tempo da Emergência (CVt) mede o grau de dispersão da emergência ao redor do tempo médio conforme Equação (4).

$$
\mathrm{CVt}=\frac{\mathrm{S}}{\mathrm{Tm}} 100
$$

Onde, "S"é o desvio padrão da emergência e "Tm" é o tempo médio da emergência. Como a emergência não é sincronizada, calcular o índice de Sincronia (Z) conforme Equação (5), visa quantificar a variação da emergência ao longo do tempo. O índice, expresso em bit, é uma 
medida binária que conta somente se a semente emerge ou não emerge, conforme Santana e Ranal (2004).

$$
\mathrm{Z}=\sum_{\mathrm{i}=1}^{\mathrm{k}} \mathrm{C}_{\mathrm{ni}, 2} / \mathrm{C}_{\mathrm{n} 1,2}, \text { com: } \mathrm{C}_{\mathrm{ni}, 2}=\mathrm{ni} \frac{(\mathrm{ni}-\mathbf{1})}{2}
$$

Onde, " $\mathrm{C}_{\mathrm{ni}, 2}$ " é a combinação duas a duas das plântulas emergidas no tempo determinado "i" e $\mathrm{n}_{\mathrm{i}}$ é o número de plântulas emergidas no tempo “i”. A Equação (6) demonstra o cálculo do índice de incerteza da emergência, proposta por Laboriau e Valadares (1976). A equação descreve a análise da Incerteza da Emergência associada com La distribuição da frequência relativa da emergência.

$$
I=-\sum_{I-1}^{K} f i \log _{2} F r
$$

Onde, "Fr", é a Frequência Relativa da Emergência, "Log2" é o logaritmo da base 2 e "K" é último dia de observação. Para estudo da distribuição da emergência ao longo do tempo experimental, os gráficos de distribuição de frequências foram construídos com base na Equação (7) utilizada para obtenção dos resultados segundo Santana e Ranal (2004), onde "Fr" é a frequência relativa da emergência, "ni" é o número de plântulas emergidas no dia "i" e "k" é o último dia de observação da emergência no experimento proposto.

$$
\mathrm{Fr}=\frac{\mathrm{ni}}{\sum_{\mathrm{i}=1}^{\mathrm{k}} \mathrm{ni}}
$$

Os dados foram submetidos à análise de variância pelo programa estatístico Sisvar versão 5.3 (FERREIRA, 2003). As médias da interação ou dos efeitos principais, respectivamente, foram comparadas pelo teste de Tukey a 5\% de probabilidade.

\section{RESULTADOS E DISCUSSÃO}

O resumo das análises de variâncias se encontra na Tabela 1. Nota-se que, de maneira geral, a interação entre as cultivares e o tempo de armazenamento se mostra significativa pelo teste $\mathrm{F}$ a $5 \%$ e a $1 \%$ de probabilidade, exceto para a germinação de sementes e para o índice de incerteza da emergência, cujo período de armazenamento se mostrou estatisticamente significativo a $1 \%$ de probabilidade pelo teste $\mathrm{F}$. 
Tabela 1-Resumo das análises de variância dos dados de Germinação (G), Emergência (E), Tempo médio de

Emergência (Tm), Coeficiente de Variação no Tempo (CVt), Índice de Velocidade de Emergência (IVE),

Incerteza (I) e Sincronia (Z) de sementes de jiló armazenadas em ambiente não controlado por até 120 dias, Bambuí/MG, 2016

\begin{tabular}{|c|c|c|c|c|c|c|c|c|c|c|c|c|c|c|c|}
\hline \multirow{2}{*}{ FV } & \multirow{2}{*}{ GL } & \multicolumn{14}{|c|}{ Quadrado Médio (QM) } \\
\hline & & $\mathbf{G}$ & & $\mathbf{E}$ & & $\mathbf{T m}$ & & $\mathbf{C V t}$ & & IVE & & $\mathbf{I}$ & & $\mathbf{Z}$ & \\
\hline Cultivar (C) & 1 & 13.5200 & & 41.4050 & & 2.0501 & $* *$ & 2.7707 & & 27.4668 & $* *$ & 0.0006 & & 0.000077 & \\
\hline Tempo (T) & 4 & 844.5800 & $* *$ & 535.2825 & $* *$ & 0.3292 & $* *$ & 7.5002 & $* *$ & 56.2865 & $* *$ & 0.0438 & $* *$ & 0.000352 & $* *$ \\
\hline $\mathrm{C} * \mathrm{~T}$ & 4 & 60.9200 & & 63.2675 & $*$ & 0.6929 & $* *$ & 4.1512 & $*$ & 18.7141 & $* *$ & 0.0095 & & 0.000127 & $*$ \\
\hline Bloco & 4 & 43.7800 & & 61.8825 & & 0.0618 & & 1.4273 & & 8.6284 & & 0.0149 & & 0.000058 & \\
\hline Erro & 36 & 32.0688 & & 22.6825 & & 0.0281 & & 1.2516 & & 2.2590 & & 0.0239 & & 0.000042 & \\
\hline $\mathrm{CV}(\%)$ & & 6,89 & & 7,06 & & 2,55 & & 3,57 & & 5,67 & & 2,06 & & 7,49 & \\
\hline
\end{tabular}

O tempo de armazenamento em condições ambientais não controladas influenciou significativamente a germinação das sementes de jiloeiro (Tabela 2). As sementes não armazenadas e que foram analisadas imediatamente após a colheita obtiveram a maior porcentagem de germinação, diferindo estatisticamente dos demais tratamentos. Quanto maior o período em que as sementes permaneçam armazenadas em condições ambientais cuja umidade relativa esteja alta, o ponto de equilíbrio higroscópico entre as sementes e o ambiente também se eleva. Dada a característica de higroscopicidade das sementes, a umidade relativa do ar é o fator mais crítico para a redução da germinação no tempo, pois elevados teores de água nas sementes aceleram o processo de deterioração em razão da intensificação da atividade respiratória, consumo de reservas, liberação de calor e proliferação de microrganismos (ROBERTS, 1973). A temperatura de armazenamento afeta diretamente a velocidade das reações bioquímicas, também acelerando a respiração e o desenvolvimento de microrganismos, de modo que a redução da temperatura e o seu controle no armazenamento beneficia a conservação de sementes ortodoxas (MARCOS-FILHO, 2015). Sementes armazenadas por um período maior de tempo em ambientes não controlados podem apresentar manifestações metabólicas e bioquímicas de deterioração características de deterioração de sementes, como a perda da permeabilidade seletiva das membranas celulares, a redução da atividade respiratória das sementes e, consequentemente, da síntese de ATP, a inativação ou redução da atividade de enzimas-chave nos processos biossintéticos, a decomposição das reservas nutritivas, o acúmulo de metabólitos tóxicos e a ocorrência de danos ao material genético (COOLBEAR, 1995; McDONALD, 1999). 


\begin{tabular}{|c|c|}
\hline Tempo de Armazenamento (dias) & Germinaçãóo $^{\top}$ \\
\hline 0 & $95 \mathrm{~A}$ \\
\hline 30 & $87 \mathrm{~B}$ \\
\hline 60 & $80 \mathrm{BC}$ \\
\hline 90 & $77 \mathrm{CD}$ \\
\hline 120 & $71 \mathrm{D}$ \\
\hline
\end{tabular}

${ }^{1}$ Médias seguidas pela mesma letra maiúscula na coluna não diferem entre si pelo teste de Tukey a 0,05 de significância. Fonte: Autor (2016).

Houve interação significativa ao analisar a Porcentagem de Emergência de Plântulas de jiloeiro entre as cultivares estudadas e o período em que as sementes permaneceram armazenadas (Tabela 3). Nota-se que, de maneira geral, a redução da emergência ocorreu a partir dos 30 dias de armazenamento para a cultivar Português e a partir dos 60 dias para a cultivar Morro Grande, corroborando com os resultados de germinação. As sementes da cultivar Português se apresentaram com maior potencial de emergência de plântulas de jiloeiro quando não foram armazenadas quando comparadas com as sementes da cultivar Morro Grande. Para a cultivar Português, nota-se uma redução considerável de Emergência de plântulas a partir dos 30 dias de armazenamento, e para a cultivar Morro Grande, a redução de Emergência se dá a partir dos 60 dias de armazenamento.

Tabela 3- Média dos dados de emergência (E) e Índice de Velocidade de Emergência (IVE), de sementes de duas cultivares de jiló armazenadas em ambiente não controlado por até 120 dias, Bambuí/MG, 2016

\begin{tabular}{ccccc}
\hline \multirow{2}{*}{ Tempo de Armazenamento (dias) } & \multicolumn{3}{c}{ Emergência $^{(E)} \mathbf{1}^{\mathbf{1}}$} \\
\cline { 2 - 5 } & Morro Grande & \multicolumn{2}{c}{ Português } \\
\hline 0 & $75 \mathrm{~A}$ & $\mathrm{~b}$ & $82 \mathrm{~A}$ & $\mathrm{a}$ \\
30 & $72 \mathrm{AB}$ & $\mathrm{a}$ & $69 \mathrm{~B}$ & $\mathrm{~b}$ \\
60 & $61 \mathrm{C}$ & $\mathrm{b}$ & $69 \mathrm{~B}$ & $\mathrm{a}$ \\
90 & $64 \mathrm{AB}$ & $\mathrm{a}$ & $64 \mathrm{BC}$ & $\mathrm{a}$ \\
120 & $60 \mathrm{C}$ & $\mathrm{a}$ & $59 \mathrm{C}$ & $\mathrm{a}$ \\
\hline
\end{tabular}

\begin{tabular}{|c|c|c|c|}
\hline \multirow{2}{*}{ Tempo de Armazenamento (dias) } & \multicolumn{3}{|c|}{ Indice de Velocidade da Emergência (IVE) ${ }^{\top}$} \\
\hline & Morro Grande & Português & \\
\hline$\overline{0}$ & $28,0625 \mathrm{~A} \quad \mathrm{~b}$ & $31,9957 \mathrm{~A}$ & $\bar{a}$ \\
\hline 30 & $28,7763 \mathrm{~A}$ & $27,0412 \mathrm{~B}$ & $\mathrm{a}$ \\
\hline 60 & $22,7660 \mathrm{~B}$ & $27,2963 \mathrm{~B}$ & $\mathrm{a}$ \\
\hline 90 & $24,5297 \mathrm{~B}$ & $25,7911 \mathrm{BC}$ & $\mathrm{a}$ \\
\hline 120 & $24,7580 \mathrm{~B}$ & $24,1800 \mathrm{C}$ & $\mathrm{a}$ \\
\hline
\end{tabular}

${ }^{1}$ Médias seguidas pela mesma letra maiúscula na coluna e minúscula na linha não diferem entre si pelo teste de Tukey a 0,05 de significância.

Fonte: Autor (2016) 
Os melhores resultados para Índice de Velocidade de Emergência (IVE) foram obtidos quando as sementes da cultivar Português não foram armazenadas. A partir dos 30 dias de armazenamento e a partir de 60 dias de armazenamento para a cultivar Morro Grande, nota-se que as sementes emergiram mais lentamente de acordo com os resultados de IVE (Tabela 03). Aliados aos dados de IVE, os resultados obtidos para o Tempo Médio da Emergência (Tm) evidenciaram que as sementes da cultivar Português se mostraram em média mais rápidas para emergir quando armazenadas por até 30 dias, o que não foi evidenciado para a cultivar Morro Grande,para todos os períodos de armazenamento (Tabela 4). Segundo Matthews (1985 apud Marcos-Filho, 2015), a manifestação inicial mais evidente do processo de envelhecimento das sementes é o declínio da velocidade de germinação das sementes, seguido pela redução do tamanho das plântulas emergidas e a ocorrência de plântulas anormais no teste de germinação.

Tabela 4- Média dos dados Tempo Médio da Emergência (Tm), Coeficiente de variação do tempo da emergência (CVt) e Sincronia $(\mathrm{Z})$ da emergência de sementes de duas cultivares de jiló armazenadas em ambiente não controlado por até 120 dias, Bambuí/MG, 2016

\begin{tabular}{|c|c|c|c|c|}
\hline \multirow{2}{*}{ Tempo de Armazenamento (dias) } & \multicolumn{4}{|c|}{ Tempo Médio da Emergência (Tm) ${ }^{\top}$} \\
\hline & \multicolumn{2}{|c|}{ Morro Grande } & \multicolumn{2}{|c|}{ Português } \\
\hline$\overline{0}$ & $6,9073 \mathrm{~B}$ & $\mathrm{~b}$ & $\overline{5,6277 \mathrm{~A}}$ & $\bar{a}$ \\
\hline 30 & $6,5387 \mathrm{~A}$ & a & $6,6873 \mathrm{~B}$ & $\mathrm{a}$ \\
\hline 60 & 6,8592 B & b & $6,5928 \mathrm{~B}$ & $\mathrm{a}$ \\
\hline 90 & $6,8351 \mathrm{AB}$ & b & $6,5421 \mathrm{~B}$ & $\mathrm{a}$ \\
\hline 120 & $6,7325 \mathrm{AB}$ & $\mathrm{b}$ & $6,3982 \mathrm{~B}$ & $\mathrm{a}$ \\
\hline \multirow{2}{*}{ Tempo de Armazenamento (dias) } & \multicolumn{4}{|c|}{ Coeficiente de Variação do Tempo $(C V t)^{T}$} \\
\hline & \multicolumn{2}{|c|}{ Morro Grande } & \multicolumn{2}{|c|}{ Português } \\
\hline 0 & $30,5764 \mathrm{~A}$ & $\mathrm{a}$ & $29,5024 \mathrm{~A}$ & $\bar{a}$ \\
\hline 30 & $30,5185 \mathrm{~A}$ & a & $31,6651 \mathrm{~B}$ & a \\
\hline 60 & $30,7850 \mathrm{~A}$ & a & $31,4774 \mathrm{~B}$ & a \\
\hline 90 & $30,9000 \mathrm{~A}$ & a & $33,0250 \mathrm{~B}$ & b \\
\hline 120 & $32,5168 \mathrm{~A}$ & $\mathrm{a}$ & $31,9808 \mathrm{~B}$ & $\mathrm{a}$ \\
\hline \multirow{2}{*}{ Tempo de Armazenamento (dias) } & \multicolumn{4}{|c|}{ Sincronia da Emergência $(\mathrm{Z})^{\top}$} \\
\hline & \multicolumn{2}{|c|}{ Morro Grande } & \multicolumn{2}{|c|}{ Português } \\
\hline 0 & $0,0780 \mathrm{~B}$ & $\bar{a}$ & $0,0892 \mathrm{AB}$ & $\mathrm{b}$ \\
\hline 30 & $0,0872 \mathrm{AB}$ & $\mathrm{a}$ & $0,0846 \mathrm{AB}$ & $\mathrm{a}$ \\
\hline 60 & 0,0792 B & a & $0,0811 \mathrm{~B}$ & a \\
\hline 90 & $0,0804 \mathrm{~B}$ & a & $0,0883 \mathrm{AB}$ & $\mathrm{a}$ \\
\hline 120 & $0,0989 \mathrm{~A}$ & $\mathrm{a}$ & 0,0929 A & a \\
\hline
\end{tabular}

${ }^{1}$ Médias seguidas pela mesma letra maiúscula na coluna e minúscula na linha não diferem entre si pelo teste de Tukey a 0,05 de significância.

Fonte: Autor (2016)

Não houve diferença estatística ao avaliar o Coeficiente de Variação do Tempo da Emergência (CVt) de sementes da cultivar Morro Grande. Sementes da cultivar Português se apresentaram menos dispersas em relação ao tempo médio de emergência quando foram 
armazenadas por até 30 dias. Nota-se que as sementes apresentaram baixa sincronia para todos os períodos de armazenamento e para as cultivares estudadas. Apesar dos resultados significativos, de maneira geral, os índices se apresentaram próximos de zero, revelando a baixa sincronia das sementes de jiló para as duas cultivares (Tabela 4).

Sementes assíncronas se revelam com altos índices de Incerteza da Emergência (Tabela 5). Apesar dos resultados de interação não se apresentarem significativos, é possível evidenciar que sementes armazenadas por 120 dias se apresentaram com a menor incerteza da emergência. Entretanto, Santana et al. (2010) relatam que Coeficientes de variação do tempo acima de $20 \%$, valores de Incerteza (I) acima de zero (I > 1,80) e de sincronia $(Z)$ próximos a zero $(Z<0,32)$ revelam processos de germinação e de emergência espalhados em relação ao tempo médio, com alto grau de incerteza e baixa sincronia.

Tabela 5 - Média dos dados de Índice de Incerteza da Emergência (I) de sementes de jiló armazenadas por até 120 dias em ambiente não controlado, Bambuí/MG,

2016

\begin{tabular}{cc}
\hline Tempo de Armazenamento (dias) & Incerteza da Emergência $^{\top}$ \\
\hline 0 & $3,6175 \mathrm{~B}$ \\
30 & $3,5858 \mathrm{~B}$ \\
60 & $3,6290 \mathrm{~B}$ \\
90 & $3,6069 \mathrm{~B}$ \\
120 & $3,4661 \mathrm{~A}$ \\
\hline
\end{tabular}

${ }^{1}$ Médias seguidas pela mesma letra maiúscula na coluna não diferem entre si pelo teste de Tukey a 0,05 de significância.

Fonte: Autor (2016).

O tempo de armazenamento em condições não controladas, com altas temperaturas e alta umidade relativa favorece a deterioração de sementes. Os resultados do experimento corroboram com os resultados obtidos por Heydecker (1972) e Delouche e Baskin (1973 apud Marcos-Filho, 2015) que, ao estudarem o processo de deterioração de sementes, identificaram uma sequência de eventos que poderiam ocorrer entre a maturidade fisiológica e morte das sementes que reduziria a viabilidade das sementes. Os autores relataram, dentre os eventos hipotéticos de identificação da perda da viabilidade, a germinação lenta, evidenciada no experimento pelos resultados do IVE e Tempo Médio da Emergência, a redução da emergência de plântulas no campo, observada pelos resultados de Porcentagem de Emergência do experimento e redução da uniformidade, obtida pelos baixos valores para o Índice de Sincronia.

Ao analisar os dados de frequência da emergência de plântulas da cultivar Português (Figura 2), nota-se que, para todos os períodos de armazenamento, houve picos de emergência entre o segundo e o quarto dia, destacando-se as sementes armazenadas por 90 e por 120 dias, 
com picos próximos dos $18 \%$. Sementes não armazenadas apresentaram picos de emergência de $13 \%$ e de $16 \%$ entre o terceiro e o quintodia. Não houve uma concentração da emergência de plântulas em um determinado período quando se analisa frequência relativa das sementes armazenadas por 30 e 60 dias.

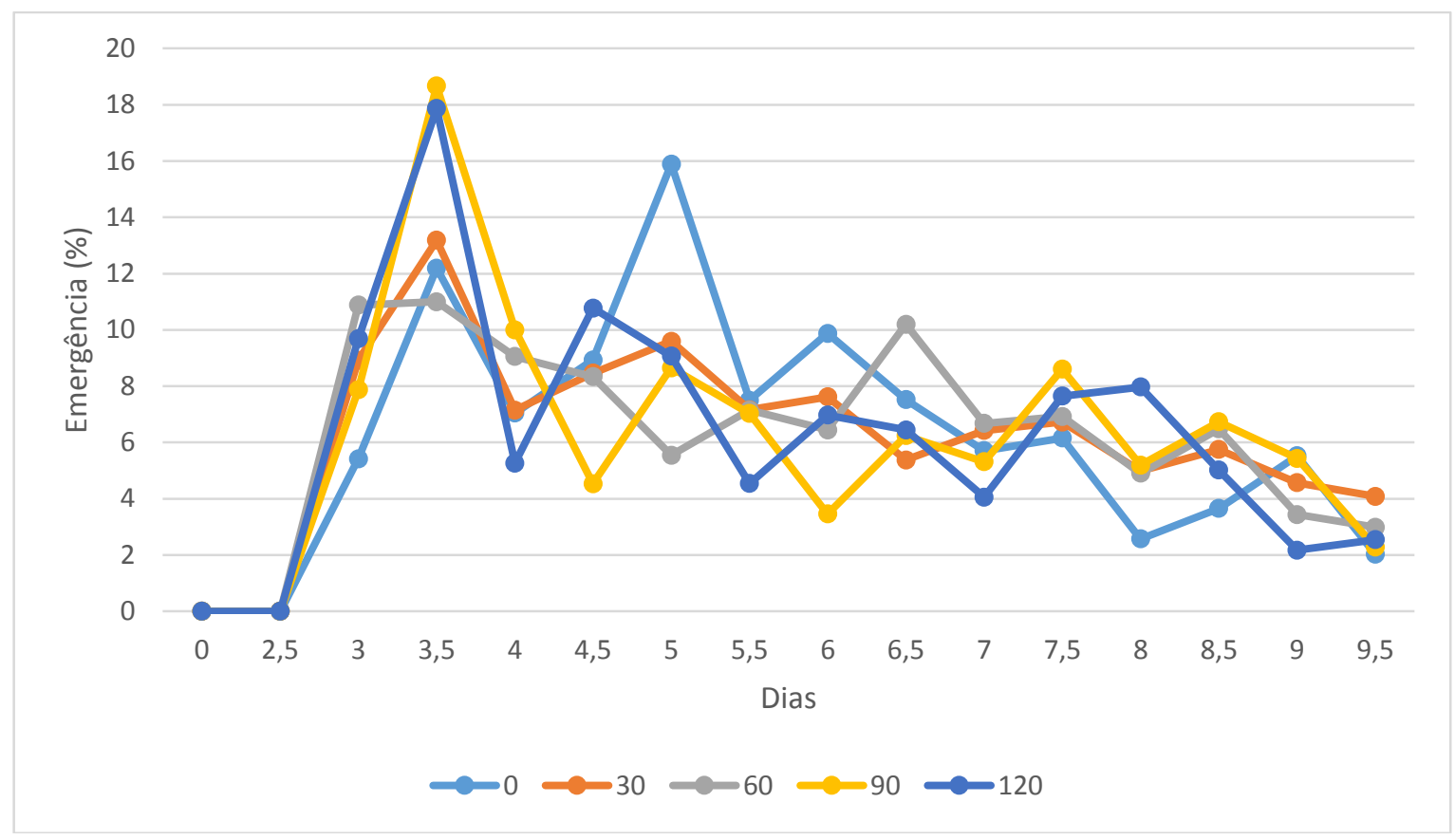

Figura 2- Média dos dados de Frequência Relativa da Emergência de sementes de jiló cultivar Português armazenadas por até 120 dias em ambiente não controlado, Bambuí/MG, 2016 Fonte: Autor (2016).

Para a cultivar Morro Grande (Figura 3), os resultados demonstram picos de emergência de plântulas variando de $11 \%$ a $15 \%$ entre o segundo e o quarto dias para todos os períodos de armazenamento. Há entre o oitavo e o nono dia, para as sementes não armazenadas, um pico de emergência de plântulas próximo dos $13 \%$ e entre o quinto e o sexto dia, para as sementes armazenadas por 120 dias, um pico de 16,5\% de emergência. De maneira geral, a alta dispersão da emergência de plântulas em relação ao tempo médio, observada pelos resultados do coeficiente de variação do tempo da emergência, para todos os períodos de armazenamento demonstram os altos índices de incerteza e menor sincronia da emergência. Apesar dos melhores resultados de germinação, emergência e IVE de sementes armazenadas por até 30 dias, para as duas cultivares estudadas, nota-se que, mesmo neste curto período de armazenamento, a emergência se revelou assíncrona e incerta. 


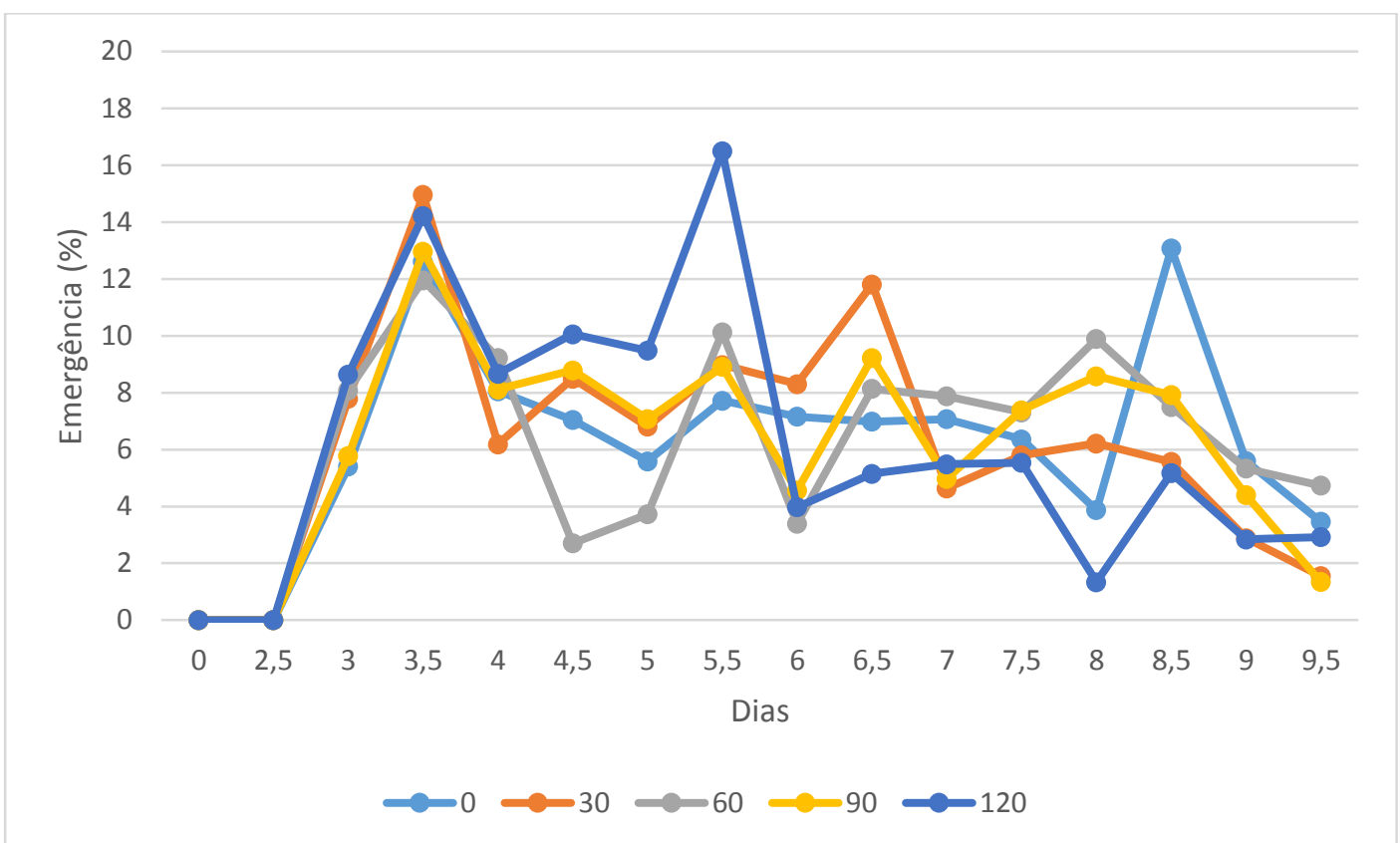

Figura 3 - Média dos dados de Frequência Relativa da Emergência de sementes de jiló cultivar Morro Grande armazenadas por até 120 dias em ambiente não controlado, Bambuí/MG, 2016

Fonte: Autor (2016).

\section{CONCLUSÕES}

A partir dos dados apresentados no trabalho, conclui-se que as sementes de jiló da cultivar Português se apresentaram com as melhores Porcentagens de Germinação e Emergência, Tempo Médio de Emergência, Índice de Velocidade de Emergência e Coeficiente de Variação do Tempo da Emergência quando armazenadas por até 30 dias em ambiente não controlado.

\section{REFERÊNCIAS}

BRASIL. Ministério da Agricultura, Pecuária e Abastecimento. Secretaria de Defesa Agropecuária. Regras para Análise de Sementes. Brasília: MAPA/ACS, 2009.

CAMARGO, L. S. As hortaliças e seu cultivo, 3 ed. Campinas: Fundação Cargill, 1992.

CARRARO, I. M. A. Importância da utilização de sementes melhoradas na agricultura moderna. Anuário Abrasem, Brasília, p. 20-23, 2004.

CARVALHO, N. M.; NAKAGAWA, J. Sementes: ciência, tecnologia e produção. 4. ed. Jaboticabal: FUNEP, 2000. 
COOLBEAR, P. Mechanisms of seed deterioration. In: BASRA, A. S. (Ed.). Seed quality: basic mechanisms and agricultural implications. New York: Food Products Press, p. 223277. 1995.

D'ARCY, W. G. The Solanaceae since 1976, with a review of its biogeography. In:

Solanaceae III: taxonomy, chemistry, evolution. London: Kew Royal Botanical Gardens, p. 75-137, 1991.

DELOUCHE, J. C.; BASKIN, C. C. Accelerated aging techniques for predicting the relative storability of seed lots. Seed Science and Technology, v. 1, n. 3, p. 427-452, 1973.

DIAS, D. C. F. S. Maturação fisiológica de sementes: o processo. Seed News, v. 5, n. 6, p. 22- 24, 2001.

ELLIS, R. H.; ROBERTS, E. H. Improved equations for the prediction of seed longevity. Annals of Botany, v. 45, n. 1, p. 13-30, 1980.

FERREIRA, D. F. Programa Sisvar.exe. Sistema de análises de variância. Versão 5.3. 2003.

FILGUEIRA, F. A. R. ABC da olericultura: guia da pequena horta. São Paulo: Agronômica Ceres, 164p., 1987.

GROOT, S. P. C. et al. Gene expression during loss and regaining of stress tolerance at seed priming and drying. In: NICOLÁS, G. et al. The biology of seeds: recent research advances. CAB International, p. 279-287, 2003.

HUNZIKER, A. T. Genera Solanacearum. The genera of Solanaceae illustrated, arranged according to a new system. Ruggell, A. R. G.Gantner Verlag. 2001.

LABOURIAU, L. F. G. A germinação de sementes. Washington: Sec. Org. dos Estados Unidos, 1983. 174p.

LABOURIAU, L. G.; VALADARES, M. E. B. On the germination of seeds Calotropis procera (Ait.) Ait.f. Anais da Academia Brasileira de Ciências, Rio de Janeiro, v. 48, n. 2, p. 263-84, 1976.

MAGUIRE, J. D. Speed of germination-aid in selection and evaluation for seedling emergence and vigor. Crop Science, Madison, v. 2, n. 1, p. 176-7, 1962.

MARCOS FILHO, J. Fisiologia de sementes de plantas cultivadas. 2. ed. Londrina: ABRATES, 2015. 660 p.

McDONALD, M. B. Seed deterioration: physiology, repair and assessment. Seed Science and Technology. Zurich, v. 7, n. 1, p. 177-237, 1999.

NAKADA, P. G. et al. Desempenho durante o armazenamento de sementes de pepino submetidas a diferentes métodos de secagem. Revista Brasileira de Sementes, Londrina, v. 32, n. 3, p. 42-51, 2010. 
PESAGRO-RIO; EMATER-RIO. Recomendações para a cultura do jiló. Niterói: Informe Técnico, n. 18, 16 p., 1986.

PIÑA-RODRIGUES, F. C. M.; FIGLIOLIA, M. B. Sementes florestais tropicais. Brasília: ABRATES, 1993. p. 215-274.

RODRIGUES, F. C. M.; AGUIAR, I. B. Maturação e dispersão de sementes. In: AGUIAR, I. B.; POPINIGIS, F. Fisiologia da semente. AGIPLAN, 289 p., 1985.

ROBERTS, E. H. Predicting the storage life of seeds. Seed Science and Technology, v. 1, p. 499-514, 1973.

SANTANA, D. G. et al. Germinação de sementes e emergência de plântulas de pau-santo: uma análise crítica do uso de correlação. Revista Brasileira de Sementes. 32: 134-140, 2010.

SANTANA, D. G.; RANAL, M. A. Análise da germinação: um enfoque estatístico. Brasília: UnB, 2004. 248p.

SILVA, R. P. et al. Qualidade fisiológica de sementes de soja (Glycine max L.) durante o beneficiamento. Semina: Ciências Agrárias, Londrina, v. 32, n. 4, p. 1219- 1230, 2011.

\section{DADOS DOS AUTORES:}

\section{Carlos Manoel Oliveira}

E-mail: carlos.manoel@ifmg.edu.br

Currículo Lattes: http://lattes.cnpq.br/8356523786026948

Doutor em Agronomia pela Universidade Federal de Uberlândia (UFU). Mestre em Agronomia (Fitotecnia) pela Universidade Federal de Lavras (UFLA). Bacharel em Agronomia pela UFU, Brasil. 